\title{
Structural and magnetic properties of Co(II) complexes with tridentate ONO pincer-type ligands
}

\author{
Veronika Chrenková, Dušan Valigura \\ Institute of Chemistry, Faculty of Natural Sciences, University of SS. Cyril and Methodius, \\ J. Herdu 2, Trnava, SK-917 01, Slovak Republic \\ veron.chrenkova@gmail.com
}

\begin{abstract}
Pincer type ligand 2,6-pyridinedimethanol was used as a useful tool in the preparation of the Co(II) pseudoctahedral complex together with 3,5-dinitrobenzoate counteranion. New complex of the composition $\left[\mathrm{Co}(\mathrm{pydm})_{2}\right](3,5-\mathrm{dnbz})_{2}($ pydm $=2,6$-pyridinedimethanol, and 3,5-dnbz $=3,5$-dinitrobenzoate anion $)$ has been prepared and characterized. Its XRD structure revealed pseudooctahedral $\left\{\mathrm{CoN}_{2} \mathrm{O}_{4}\right\}$ chromophore around

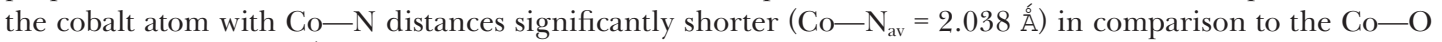
ones $\left(\mathrm{Co}-\mathrm{O}_{\mathrm{av}}=2.142 \AA\right.$ ) , which was probably the reason of its relatively high zero-field splitting parameter $\left(D / \mathrm{hc}=43.6 \mathrm{~cm}^{-1}\right)$. Positive value of the $D$ parameter causes slow relaxation process typical for Co(II) SMM behavior. The 3,5-dinitrobenzoate counteranions are strongly bonded to the $\left[\mathrm{Co}(\mathrm{pydm})_{2}\right]$ cation via rather

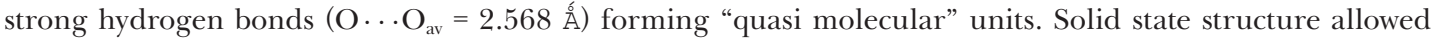
different $\pi$ - $\pi$ stacking interactions of neighboring "molecular" unit aromatic rings probally leading to observation of the additional relaxation mode.
\end{abstract}

Keywords: cobalt(II) complex, pincer type ligand, 2,6-pyridinedimethanol, structure and magnetism

\section{Introduction}

Pincer like ligands are tridentate ligands that have been frequently studied during the last two decades due to their complex formation ability in different fields from basic coordination chemistry through biological applications of complexes to their catalytic activity in many differentsyntheses(Morales-Morales, 2007; Van Koten, 2011). Transition metal complexes, including complexes of $\mathrm{Co}(\mathrm{II})$, represent a very interesting area due to the large variability of central atom properties as well as the variability of ligand effects on the complex resulting properties including possible interactions of the complex particles. Moreover, structures of the copper(II) complex containing two different pincer type ligands $[\mathrm{Cu}(\mathrm{pydm})$ (pydc)] (where pydc =2,6-pyridinedicaboxylate $(2-)$ anion, and pydm =2,6-pyridinedimethanol) (Koman, 2000) and later also three complexes $[\mathrm{M}(\mathrm{pydm})$ (pydc) $] \cdot \mathrm{H}_{2} \mathrm{O}$ (where $\mathrm{M}=\mathrm{Co}, \mathrm{Ni} \mathrm{Zn}$ ) (Uçar, 2013) have confirmed the dominant structural influence of the pincer type ligands. In addition, systematic study of magnetic properties of these complexes has revealed SMM properties of $\left[\mathrm{Ni}\left(\right.\right.$ pydm) $($ pydc) $] \cdot \mathrm{H}_{2} \mathrm{O}$ (Miklovič, 2015) and slow magnetic relaxation for complex $\left[\mathrm{Cu}(\right.$ pydm)(pydc) $] \cdot \mathrm{H}_{2} \mathrm{O}$ (Boča, 2017).

In previous papers devoted to the $\mathrm{Co}^{\mathrm{II}}$ complexes (Papánková, 2010; Hudák, 2011; Idešicová, 2012; Šebová, 2012; Titiš, 2012; Hudák, 2013) it was shown that these complexes represent a whole range of interesting objects for magnetochemistry - from simple paramagnetic substances to Single Molecule Magnet
(SMM). Moreover, it was found that the magnetic properties are in a certain relation to the zero-field splitting parameter $D$ value and, additionally, there is a good correlation between the structural characteristic $D_{\text {str }}$ of the $\mathrm{Co}^{\mathrm{II}}$ coordination polyhedra and the zero-field splitting $D$ parameter (Titiš, 2011), which is the reason for focusing our research on Co(II) complexes with pincer type 2,6-pyridinedimethanol ligand (Valigura, 2017). This work is oriented on the less "assymetric" complex Co(II) with 2,6-pyridinedimethanol molecules only in the coordination sphere to evaluate mainly the structural infuence in the $\left[\mathrm{Co}(\text { pydm })_{2}\right](3,5 \text {-dnbz })_{2}$ complex.

\section{Experimental}

Synthesis of complex $\left[\mathrm{Co}(\text { pydm })_{2}\right](3,5-\mathrm{dnbz})_{2}$

Ligand 2,6-pyridinedimethanol (1 mmol) was added to $40 \mathrm{ml}$ of choosen solvent (water - sample VCH04, ethanol - sample VCH05 or acetonithrile - VCH06) containing cobalt(II) acetate $(1 \mathrm{mmol})$ under stirring. Then, 3,5-dinitrobenzoic acid ( $2 \mathrm{mmol})$ was added to the reaction mixture and stirred at laboratory temperature until color stabilization, or slightly warmed to $40{ }^{\circ} \mathrm{C}$ in case of poor solubility. Chemicals reacted in the stoichiometric ratio $1: 1: 2$ (salt : ligand : acid). Reaction mixtures were left to crystallize at ambient temperature. Subsequently, the crystals were filtered off, washed with a small amount of appropriate solvent and dried in air at ambient temperature. Mother liquids were left for another crystallization at laboratory temperature. 
Anal Calc for $\left[\mathrm{Co}(\text { pydm })_{2}\right](3,5-\mathrm{dnbz})_{2}: \mathrm{C}, 44.28 ; \mathrm{H}$, 3.18; N, 11.07. Found for VCH04: C, 44.2; H, 3.0; N, 11.0.

Anal Calc for $\left[\mathrm{Co}(\text { pydm })_{2}\right](3,5-\mathrm{dnbz})_{2}: \mathrm{C}, 44.28 ; \mathrm{H}$, 3.18; N, 11.07. Found for VCH05: C, 43,7; H, 3.0; $\mathrm{N}, 10.9$.

Anal Calc for $\left[\mathrm{Co}(\mathrm{pydm})_{2}\right](3,5-\mathrm{dnbz})_{2}: \mathrm{C}, 44.28 ; \mathrm{H}$, 3.18; N, 11.07. Found: C, for VCH06 44.2; H, 2.9; $\mathrm{N}, 11.0$.

\section{Materials and methods}

Analytical grade chemicals from Sigma-Aldrich were used without further purification. Carbon, hydrogen and nitrogen analyses were carried out on a CHNSO FlashEA ${ }^{\mathrm{TM}} 1112$ Automatic Elemental Analyzer. Infrared spectra $\left(4000-400 \mathrm{~cm}^{-1}\right)$ were measured on a MAGNA 750 IR Nicolet spectrometer using the ATR technique. Electronic spectra (200-1100 nm) of the complexes were measured using a SPECORD 250 Plus (Carl Zeiss Jena).

Magnetic susceptibility measurements of the choosen sample were carried out on a SQUID magnetometer MPMS-XL7, Quantum Design. Raw susceptibility data were corrected for the underlying diamagnetism, converted to the effective magnetic moment and they were subject to further analysis (for details see Discussion).

\section{Results and Discussion}

Ligand 2,6-pyridinedimethanol (Figure 1 on the left) is, due to its planar structure, able to be bonded in the mer-coordination mode (Uçar,
2013; Boča, 2017; Husáriková, 2013). The anion of 3,5-dinitrobenzoic acid (Fig. 1 on the right) was chosen for its ability to act as a noncoordinated anion or in different covalent bonding ranging from monodentate covalent to bidentate chelate bonding mode and even bidentate bridging bonding ligand.<smiles>OCc1cccc(CO)n1</smiles><smiles>O=C(O)c1cc([N+](=O)[O-])cc([N+](=O)[O-])c1</smiles>

Fig. 1. Structure of 2,6-pyridinedimethanol (left) and 3,5-dinitrobenzoic acid.

The aim of this work is to study the preparation of Co(II) complexes with the above mentioned ONO "pincer-type" ligands in the presence of a carboxylate anion in different solvents to check if different conditions lead to different products. The obtained products have shown similar composition (see experimental part) alowing to attribute the same formula, $\left[\mathrm{Co}(\text { pydm })_{2}\right](3,5-\mathrm{dnbz})_{2}$, for all obtained products. Moreover, all products exhibited similar infrared spectral properties (Fig. 2).

Electron spectra of the prepared produts were recorded in the solid phase and they are also very similar confirming thus the same structure of the synthesized products (Fig. 3). In the area of $18000 \mathrm{~cm}^{-1}$, typical peak characteristic for pure octahedral complexes can be observed. Slight dif-

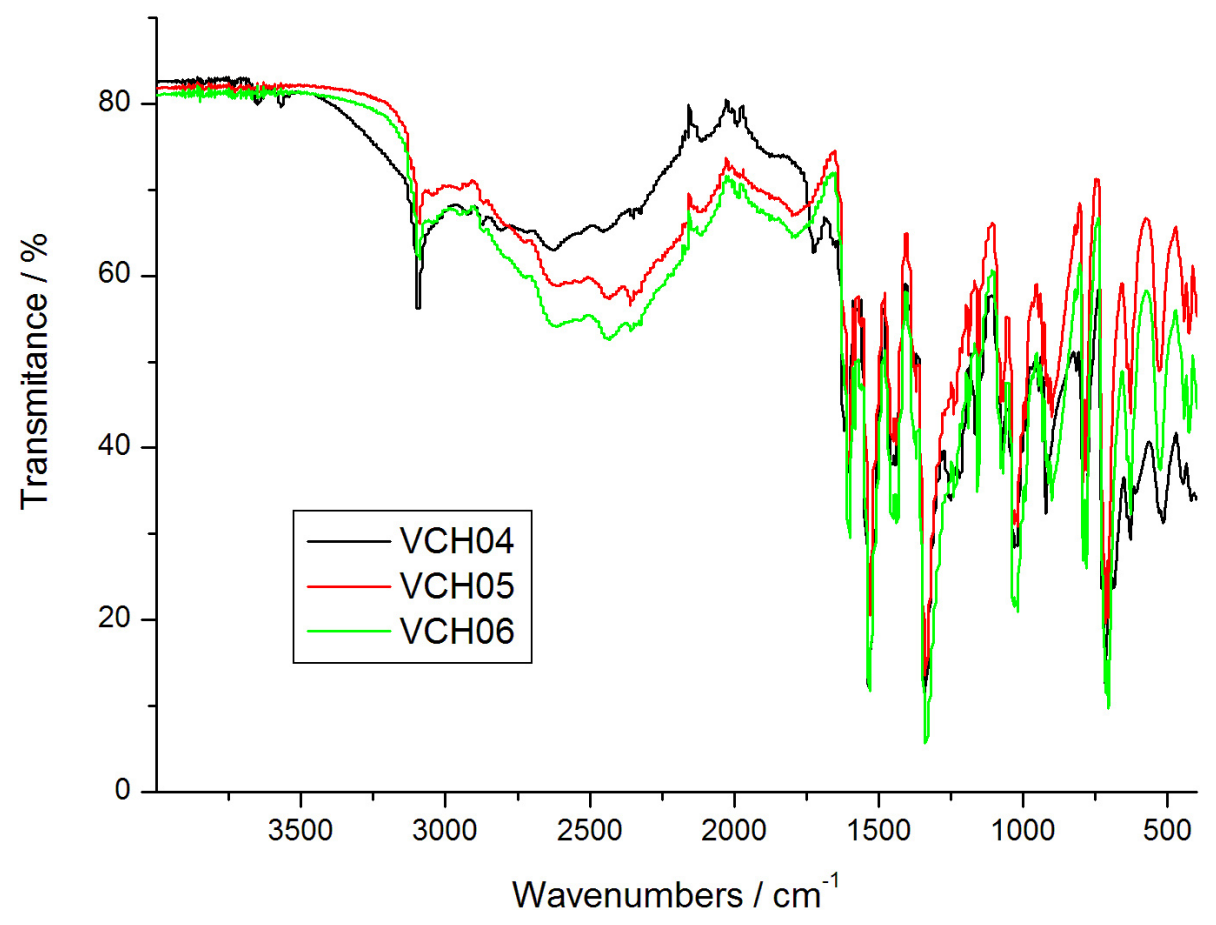

Fig. 2. Infrared spectra for samples VCH04-VCH06. 


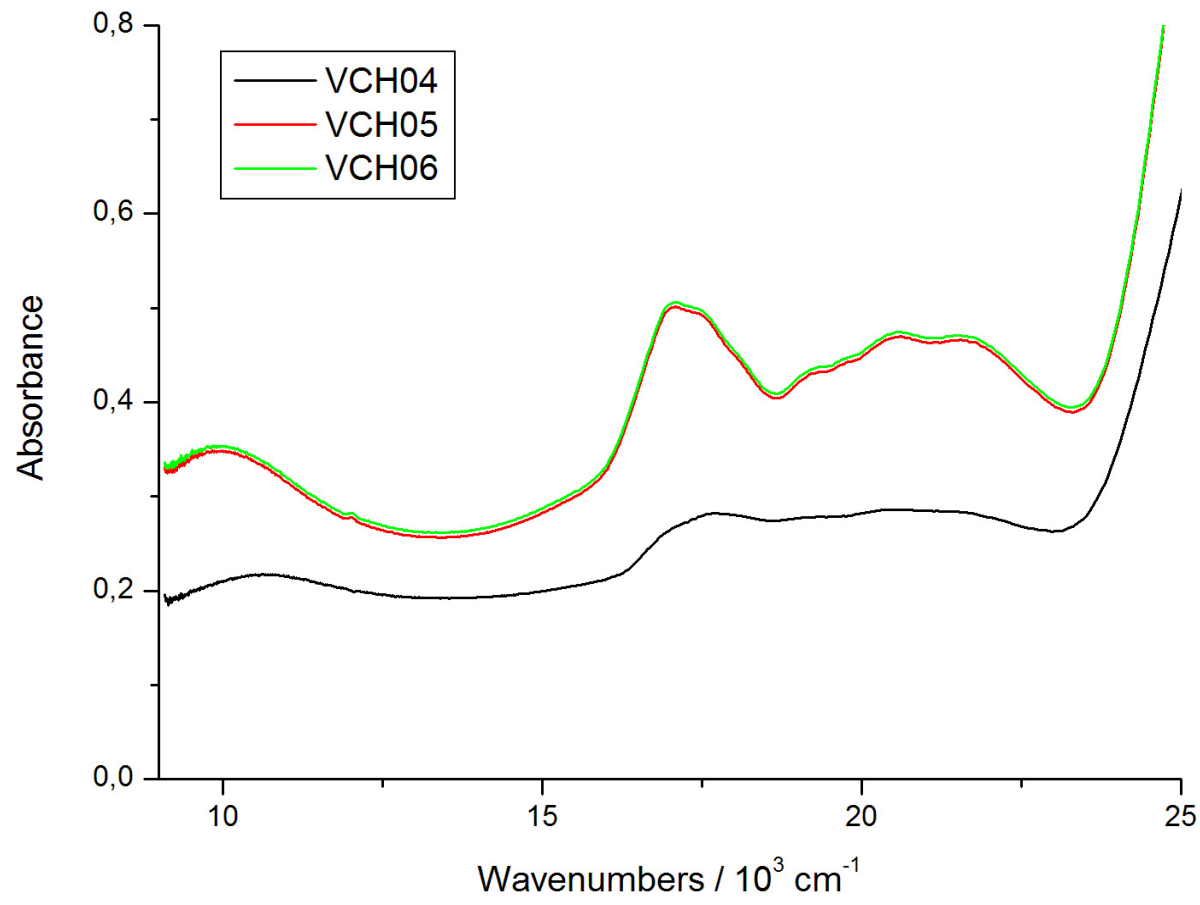

Fig. 3. Solid-state electron spectra for samples VCH04-VCH06 taken in the Nujol suspension (Specord 250 Plus spectrometer, Analytica Jena). Peak assignment in the octahedral approximation:

$$
{ }^{4} \mathrm{~T}_{2 \mathrm{~g}} \leftarrow{ }^{4} \mathrm{~T}_{1 \mathrm{~g}}(\mathrm{~F})[10600],{ }^{4} \mathrm{~A}_{2 \mathrm{~g}} \leftarrow{ }^{4} \mathrm{~T}_{1 \mathrm{~g}}(\mathrm{~F})[17700] \text { and }{ }^{4} \mathrm{~T}_{1 \mathrm{~g}}(\mathrm{P}) \leftarrow{ }^{4} \mathrm{~T}_{1 \mathrm{~g}}\left[20500 \mathrm{~cm}^{-1}\right] \text {. }
$$

ference from the standard is the fact that the strip continues up to $23000 \mathrm{~cm}^{-1}$, which can be related to deformed geometry of the complex and the properties of the used pincer-type ligand. The same phenomenon was also described in another papers (Hudák, 2011), where the increased intensity of this stripe is attributed to forbidden transitions.

Suitable crystals obtained from the mother liquid of the VCH04 product alowed obtaining data for structural analysis. The compound crystallizes in the triclinic space group $P-1$. Crystal structure of the complex consists of two uncoordinated 3-nitrobenzoate anions and one complex cation $\left[\mathrm{Co}(\text { pydm })_{2}\right]^{2+}$. The cobalt(II) ion is hexacoordinated by a pair of neutral 2,6-pyridinedimethanol molecules constituting a $\left\{\mathrm{CoN}_{2} \mathrm{O}_{4}\right\}$ chromophore (Fig. 4). Each pydm ligand acts as a tridentate ligand through the pyridine nitrogen atom and two hydroxyl oxygen atoms forming two five-membered symmetric chelate rings.

An analysis of the obtained structure showed some interesting features. According to its formula, complex $\left[\mathrm{Co}(\text { pydm })_{2}\right](3,5-\mathrm{dnbz})_{2}$ can be considered as a ionic structure but the hydrogen bonds between the complex cation $\left[\mathrm{Co}(\mathrm{pydm})_{2}\right]^{2+}$ and both carboxylate anions are rather strong hydrogen bonds (Donor...Acceptor distances of 2.532-2.591 Å) (Fig. 4), which can also be interpreted as molecular structure. The other fact that should be stressed is the coordination polyhedron of the cobalt atom in this complex described as the geometry of highly deformed compressed octahedron (see bond lenghts and/or angles under Fig. 4). Also,its brown-pink color differs from the commonly known light pink color of more regular octahedral complexes, which is probably related to the geometric properties of the used pincer-type ligand. The distorsion parameter $\sum$ calculated of twelve unique bond angles (Halcrow, 2011) gave the value $\sum=-14.05$ thus confirming deformation of the cobalt coordination polyhedron.

In addition, building blocks of the structure are arranged (Fig. 5) so that the weak $\pi-\pi$ stacking interactions of the pydm pyridine rings are allowed between neighbouring ligands. The different distances between the pyridine ring centroids $\left(c_{\mathrm{g}}-c_{\mathrm{gi}}\right.$ distance of 4.24 or $3.83 \AA$ ) show the possibility of different interactions between the neighbouring units; thus, this substance is potentially interesting for its magnetic properties. For this reason, the sample was subjected to a magnetometric study and complete magnetostructural profile has been published (Valigura, 2017).

Magnetic data were measured using a powder load of $35.36 \mathrm{mg}$, sealed in a gelatin capsule placed in a measuring chamber at the temperature of $5 \mathrm{~K}$. Magnetic moment was measured in two modes - temperature dependence at the interval $T=1.9-300 \mathrm{~K}$ at low field $B=0.1 \mathrm{~T}$ and field dependence to $B=0-7.0 \mathrm{~T}$ at low temperature $T=2.0$ and $4.6 \mathrm{~K}$.

Effective magnetic moment at room temperature acquires value $\mu_{\text {eff }}=4.05 \mu \mathrm{B}$ (Fig. 6) which is 


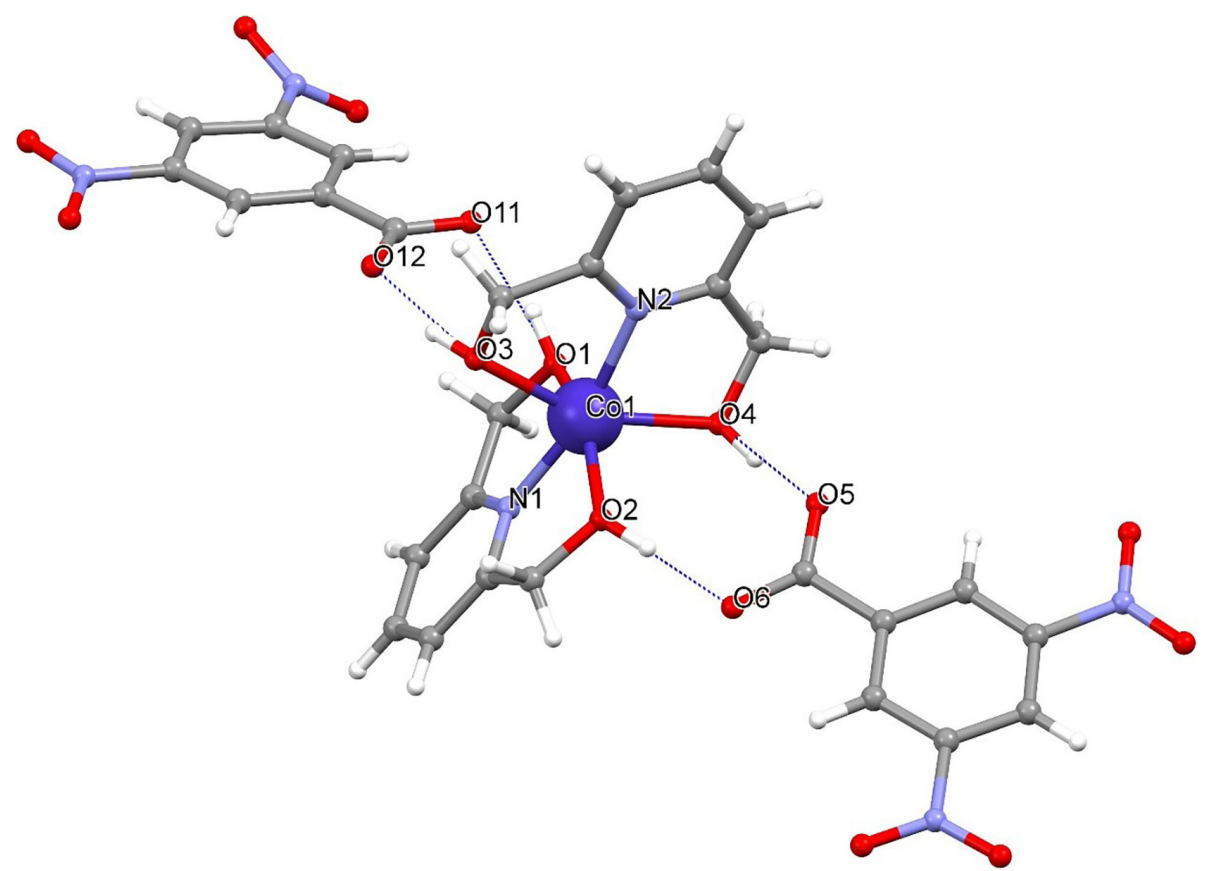

Fig. 4. Structure of $\left[\mathrm{Co}(\mathrm{pydm})_{2}\right](3,5-\mathrm{dnbz})_{2}$ complex. Bond lenghts: $\mathrm{Co} 1-\mathrm{O} 1=2.1455(13)$, $\mathrm{Col}-\mathrm{O} 2=2.0777(13), \mathrm{Co} 1-\mathrm{O} 3=2.1855(14), \mathrm{Co} 1-\mathrm{O} 4=2.1580(13), \mathrm{Co} 1-\mathrm{N} 1=2.0364(16)$, $\mathrm{Co} 1-\mathrm{N} 2=2.0403(16)$ Á. Bond angles: $\mathrm{O} 1-\mathrm{Co} 1-\mathrm{O} 3=95.71(5), \mathrm{O} 1-\mathrm{Co} 1-\mathrm{O} 4=89.46(5)$,

$\mathrm{O} 2-\mathrm{Co} 1-\mathrm{O} 1=151.88(5), \mathrm{O} 2-\mathrm{Co} 1-\mathrm{O} 3=96.06(5), \mathrm{O} 2-\mathrm{Co} 1-\mathrm{O} 4$ 90.96(5),

$\mathrm{O} 4-\mathrm{Co} 1-\mathrm{O} 3=154.16(5), \mathrm{N} 1-\mathrm{Co} 1-\mathrm{O} 1=76.65(6), \mathrm{N} 1-\mathrm{Co} 1-\mathrm{O} 2=77.68(6)$,

$\mathrm{N} 1-\mathrm{Co} 1-\mathrm{O} 3=91.06(6), \mathrm{N} 1-\mathrm{Co} 1-\mathrm{O} 4=114.76(6), \mathrm{N} 1-\mathrm{Co} 1-\mathrm{N} 2=166.77(6)$,

$\mathrm{N} 2-\mathrm{Co} 1-\mathrm{O} 1=99.31(6), \mathrm{N} 2-\mathrm{Co} 1-\mathrm{O} 2=108.22(6), \mathrm{N} 2-\mathrm{Co} 1-\mathrm{O} 3=76.70(6)$, $\mathrm{N} 2-\mathrm{Co} 1-\mathrm{O} 4=77.48(6)^{\circ}$.

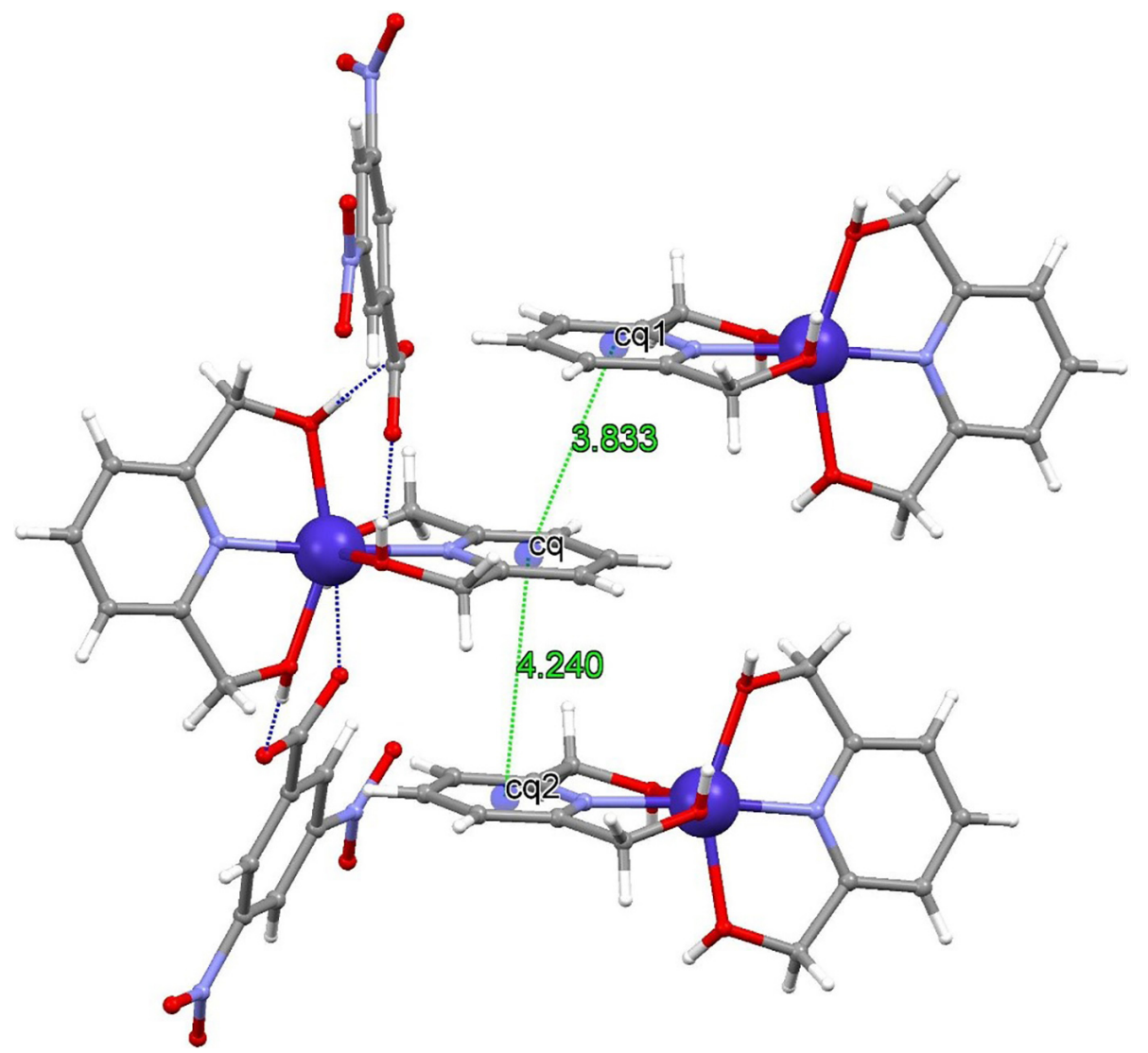

Fig. 5. Illustration of $\pi-\pi$ interactions in the $\left[\mathrm{Co}(\mathrm{pydm})_{2}\right](3,5-\mathrm{dnbz})_{2}$ complex. 

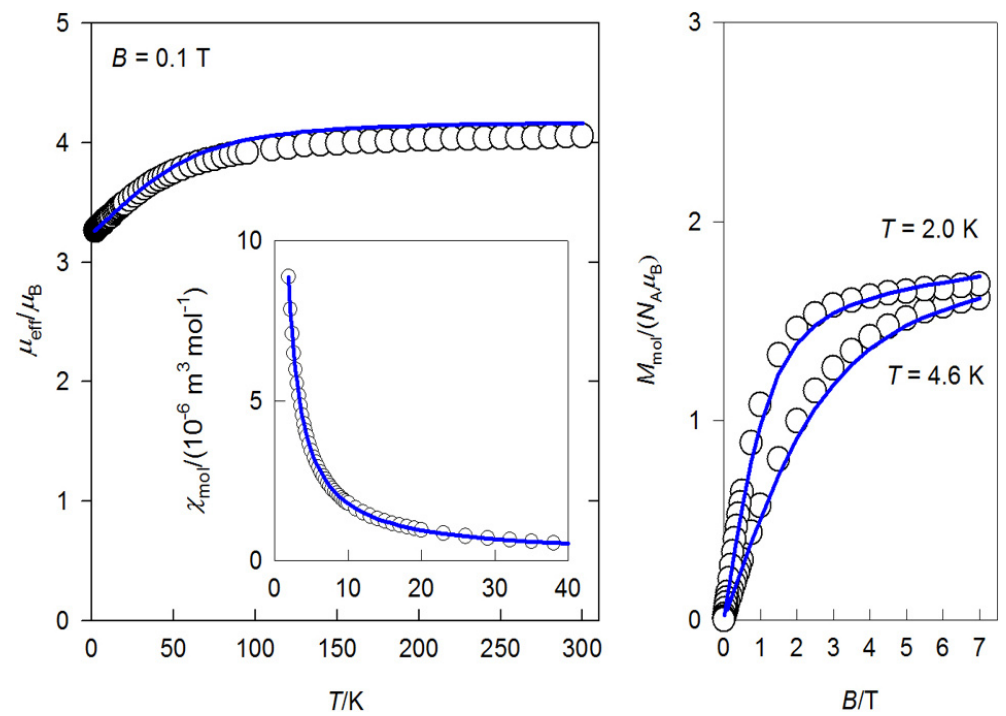

Fig. 6. Magnetic functions measured for the VCH04 sample (open circles - experimental data, lines - fitting data connections.

typical for mononuclear Co(II) complexes with the spin $S=3 / 2$ and three unpaired electrons. This value remained almost constant up to $100 \mathrm{~K}$ when a gradual decrease occurred to $\mu_{\mathrm{eff}}=3.27 \mu \mathrm{B}$ at the temperature $T=1.9 \mathrm{~K}$. This decrease is associated with the depopulation of the magnetically yielding level with the projection of $M_{S}= \pm 3 / 2$ in favor of the baseline state with $M_{S}= \pm 1 / 2$. This phenomenon is referred to by the term of zero-field splitting. A traditional zero-field splitting model utilizes the spin Hamiltonian in the form:

$$
\hat{H}_{k l}=D\left(\hat{S}_{z}^{2}-\vec{S}^{2} / 3\right) \hbar^{-2}+E\left(\hat{S}_{x}^{2}-\hat{S}_{y}^{2}\right) \hbar^{-2}+\hat{H}_{k l}^{\mathrm{z}}
$$

where $D(E)$ are the axial (rhombic) zero-field splitting parameters. The Zeeman term:

$$
\hat{H}_{k l}^{\mathrm{Z}}=\mu_{\mathrm{B}} \hbar^{-1} B\left(g_{z} \cos \vartheta_{k}+g_{x} \sin \theta_{k} \cos \phi_{l}+g_{y} \sin \theta_{k} \sin \phi_{l}\right)
$$

depends on the polar angles forming 120 knots distributed uniformly over one hemisphere.

As a result, the fitting procedure converged to the following set of magnetic parameters: $D / h c=43.6 \mathrm{~cm}^{-1}$, $E / h c=24.5 \mathrm{~cm}^{-1}, g_{z}=2.002$ and $g_{x, y}=2.216$. This dataset is consistent with the geometry of a compressed tetragonal bipyramid for $\mathrm{Co}$ (II) complexes of the $\mathrm{D}_{4 \mathrm{~h}}$ geometry.

\section{Conclusion}

All presented syntheses have produced $\left[\mathrm{Co}(\mathrm{pydm})_{2}\right]$ $(3,5 \text {-dnbz })_{2}$ complexes that were characterized by elemental analysis, infrared and electron spectra. Crystal structure of the obtained crystal has confirmed the quasi molecular structure in which the $\left[\mathrm{Co}(\text { pydm })_{2}\right]^{2+}$ cation is strongly bonded with two 3,5-dnbz ${ }^{1-}$ anions resulting in the single-molecule magnet (SMM) behavior of the product.

\section{Acknowledgement}

This work was supported by the Slovak grant agencies in the framework of projects APVV-14-0078, APVV-140073, and VEGA 1/0534/16.

\section{References}

Boča R (2004) Coord. Chem. Rev. 248: 757-815.

Boča R, Rajnák C, Titiš J, Valigura D (2017) Inorg. Chem. 56: 1478-1482.

Halcrow MA (2011) Chem. Soc. Rev. 40: 4119-4142.

Hudák J, Boča R, Dlháň L, Kožǐšek J, Moncol' J (2011) Polyhedron 30: 1367-1373.

Hudák J, Boča R, Moncol' J, Titiš J (2013) Inorg. Chim. Acta, 394: 401-409.

Husáriková L, Repická Z, Moncol' J, Valigura D, Valko M, Mazúr M (2013) Appl. Magn. Reson. 44: 571-582.

Chrenková V (2017) Diploma thesis, UCM Trnava.

Idešicová M, Dlháň L, Moncol' J, Titiš J, Boča R (2012) Polyhedron 36: 79-84.

Morales-Morales D, Jensen CM (2007) The Chemistry of Pincer Compounds. Elsevier, Amsterdam.

Miklovič J, Valigura D, Boča R, Titiš J (2015) Dalton Trans. 44: 12484-12487.

Papánková B, Boča R, Dlháň L', Nemec I, Titiš J, Svoboda I, Fuess H (2010) Inorg. Chim. Acta 363: $147-156$.

Šebová M, Boča R, Dlháň L', Nemec I, Papánková B, Pavlík J, Fuess H (2012) Inorg. Chim. Acta 383: 143-151.

Titiš J, Boča R (2011) Inorg. Chem. 50: 11838-11845.

Titiš J, Hudák J, Kožíšek J, Krutošíková A, Moncol' J, Tarabová D, Boča R (2012) Inorg. Chim. Acta 388: 106-113.

Uçar I, Tamer O, Sariboga B, Büyükgüngör O (2013) Solid State Sciences 15(1): 7-16.

Van Koten G, Klein Gebbink RJM (2011) Dalton Trans. 40: 8731-8732.

Valigura D, Rajnák C, Moncol' J, Titiš J, Boča R (2017) Dalton Trans. 46: 10950-10956. 